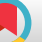

\title{
Does Physical Activity Could Moderate Perceived Wellness of Health Providers?
}

\author{
Jeyran Ostovarfar, ${ }^{1}$ Mohammad Hossein Kaveh, ${ }^{2,}{ }^{*}$ Leila Ghahremani, ${ }^{3}$ Salma Radmanesh, ${ }^{4}$
}

\author{
Mohammad Fararooei, ${ }^{5}$ and Ahmad Maghsoudi ${ }^{6}$ \\ ${ }^{1}$ Student, Department of Health Education and Promotion, School of Health, Shiraz University of Medical Sciences, Shiraz, IR Iran \\ ${ }^{2}$ Assosiat Professor, Department of Health Education and Promotion, School of Health, Shiraz University of Medical Sciences, Shiraz, IR Iran \\ ${ }^{3}$ Assistant Professor, Department of Health Education and Promotion, School of Health, Shiraz University of Medical Sciences, Shiraz, IR Iran \\ ${ }^{4}$ Assistant Professor, Cardiovascular Research center, Shiraz University of Medical Sciences, Shiraz, IR Iran \\ ${ }^{5}$ Assosiat Professor, Department of Epidemiology, School of Health, Shiraz University of Medical Sciences, Shiraz, IR Iran \\ ${ }^{6}$ Student Research Committee, Shiraz University of Medical Sciences, Shiraz, IR Iran \\ "Corresponding author: Mohammad Hossein Kaveh, Assosiat Professor, Department of Health Education and Promotion, School of Health, Shiraz University of Medical \\ Sciences, Shiraz, IR Iran. Tel: +71-37251001, Fax: +713-7260225, E-mail: kaveh@sums.ac.ir
}

Received 2017 June 11; Revised 2017 August 06; Accepted 2017 September 27.

\begin{abstract}
Background: Sufficient levels of physical activity are an issue for health, quality of life, and more importantly for healthcare providers. This study aimed to determine the status of physical activity and its relationship with perceived wellness in healthcare workers.

Methods: This study included about 254 health personnel who work in urban health centers in Shiraz. The IPAQ and PWS selfadministered questionnaires were used to collect information. This study was approved by the ethic and council committee of the Shiraz University of Medical Sciences. Additionally, moral considerations (confidentiality and informed consent) was observed, and data were analyzed with SPSS V.19.IBM.

Results: About $46 \%$ of the participants had moderated to severe physical activity. The results indicated a strong relationship between physical activity, perceived health and all its dimensions, except for social health and mental health. Furthermore, perceived health was significantly associated with age $(\rho=0.039, \beta=0.61)$ and gender $(\rho=0.002, \beta=9.33)$.

Conclusions: Regarding the staff's insufficient physical activity, the strong relationship between physical activity and health. Their impact on the organization's direct and indirect costs, health promotion programs and policies have to be designed focusing on the staff's physical activity.
\end{abstract}

Keywords: Physical Activity, Health, Perception

\section{Background}

Background: Nowadays, obesity and being overweight are among the most important health problems in developing and developed countries (1). On the other hand, physical activity has protective effects against chronic disorders, depression, and anxiety. Thus, getting used to an active lifestyle is essential for ones health (2) and decreases the risk of early death and cardiovascular diseases (3). In the U.S., physical activity programs reduced absence from work from $32 \%$ to $6 \%$, decreased healthcare costs from $55 \%$ to $20 \%$, and increased production from $2 \%$ to $52 \%$. In Canada, these programs also resulted in saving 513 dollars per staff (4). On the other hand, sedentary occupations are followed by fatigue and physical problems over time. Therefore, not only physical activity improves staff's health and performance, but it also increases production, social function, cooperation spirit, communication, job satisfaction, order, leadership, and self-control and decreases damages (5).

Frank et al. conducted a study entitled "Physical activity levels and counseling practices of U.S. medical students" and stated that physicians and other health specialists were among the major sources of information about health and exercise. They also revealed the role of consultation by primary care specialists in enhancing patients' cooperation in physical activities. Additionally, their study results showed a positive correlation between medical students' physical activity and their exercise advices (6). 


\section{Objectives}

Such individuals' health, in turn, plays a key role in these organizations' productivity. However, no studies have assessed the level of physical activity and its relationship with health as well as its dimensions among the staff of universities of medical sciences in Iran to design plans for promotion of their health at least at the organizational level. Thus, the present study aims to investigate the physical activity status and its relationship with perceived health and its dimensions among the staff.

\section{Methods}

This descriptive-analytical study aimed to assess perceived health and its relationship with physical activity level among the health personnel who work in urban health centers in Shiraz University of Medical Sciences. The study was conducted on 254 health personnel who work in urban health centers in Shiraz University of Medical Sciences selected through convenience sampling. It should be noted that the sample size was calculated using below formula and prevalence of $0.28 \%$.

$n=\frac{Z_{1-\frac{\alpha}{2}} p(1-p)}{d^{2}}$

After referring to the colleges, the researcher introduced herself to the staff and explained the study objectives. Considering ethical issues, the participants were reassured regarding the confidentiality of their information and their oral informed consents for taking part in the study were obtained. Then, the study questionnaires were given to the participants. It should be mentioned that the questionnaires were answered anonymously. The inclusion criteria of the study included individuals willing to take part in the study, working in the Shiraz University of Medical Sciences. On the other hand, the exclusion criteria included filling out the questionnaires incompletely and not being willing to take part in the study.

The study data were collected using a questionnaire including 3 parts, the first of which contained demographic information. The second part was the short form of the international physical activity questionnaire (IPAQ) used to assess the level of activity in the study population. Finally, the third part included the perceived wellness scale (PWS).

In this study, the staff's activity level was computed based on the amount of energy consumed per week (met/cal/week) and was compared to the IPAQ scores. In addition, the physical activity level was classified into mild, moderate, and severe categories based on the world health organization's (WHO) recommendations (7). Accordingly, low physical activity involved not reporting any activity or consuming less than $600 \mathrm{met} / \mathrm{cal} /$ week energy. Moderate physical activity referred to consumption of $600-3000$ met/cal/week energy. Finally, severe physical activity was defined as consumption of more than 3000 met/cal/week energy (8).

IPAQ has been used in 90 countries and its reliability and validity have been confirmed (9). The reliability and validity of this questionnaire have also been approved in various studies in $\operatorname{Iran}(3,10,11)$.

In the current study, perceived health was evaluated using the 36-item PWS designed by Adams et al. (12, 13). PWS is a salutogenically oriented, multidimensional measure of perceived wellness perceptions in physical, spiritual, psychological, social, emotional, and intellectual dimensions. Each dimension is represented by 6 items. The dimensional scores are integrated by combining the magnitude or mean of each dimension with the balance of or standard deviation among the dimensions into a composite wellness score. This questionnaire includes 21 positive and 9 negative questions randomly placed on the scale. The items are responded through a 6-point Likert scale, with $6,5,4,3,2$, and 1 scores being allocated to completely agree, agree, almost agree, almost disagree, disagree, and completely disagree, respectively. However, negative questions are scored reversely. The total score of the questionnaire could range from 36 to 216, with higher scores representing better perceived health. It should be noted that the total score of each dimensions is calculated by dividing the score of that dimension by the number of its questions (12-14).

The reliability and validity of PWS were not assessed in Iran. Therefore, the researcher conducted a pilot study on 180 samples. The results indicated Cronbach's alpha of 0.87 for the whole questionnaire. Additionally, the reliability of the scale was approved by Spearman-Brown correlation coefficient using split-half method (0.85) (15).

After all, the data were entered into the SPSS statistical software (version 17) and were analyzed using descriptive and inferential statistics. At first, univariate analysis was done to assess the effects of demographic features and physical activity on the staff's health. Then, the variables with $\mathrm{P}<0.2$ were selected for the regression model and multivariate regression analysis was performed.

\section{Results}

This study was conducted on 254 staff of Shiraz University of Medical Sciences with the mean age of $34.29 \pm$ 7.97 years. The staffs' mean of working experience was 9.78 \pm 7.14 years and their Body Mass Index (BMI) was $23.84 \pm$ 4.14. Moreover, the mean score of their perceived health was $142.94 \pm 18.36$. 
According to Table 1, most of the study participants were female (83.90\%) and married (56.30\%). Additionally, half of the participants had above bachelor's degrees, while nearly $10 \%$ did not have an academic education. Furthermore, BMI of almost two thirds of the participants was normal. Moreover, $37 \%$ of the participants had moderate to severe physical activity (8.7\%), $(\mathrm{P}<0.05)$.

Table 1. Frequency Distribution of Sex, Marital Status, Education Level, Occupation, and BMI Among the Study Participants

\begin{tabular}{lcc}
\hline Variables & Variable Levels & No. (\%) \\
\hline Sex & Male & $41(16.10)$ \\
Marital status & Female & $213(83.90)$ \\
& Single & $111(43.70)$ \\
\hline \multirow{2}{*}{ Education level } & Married & $143(56.30)$ \\
& Diploma and below & $26(10.20)$ \\
& Bachelor's degree & $121(39.80)$ \\
\hline BMI & Master's degree and above & $127(50.00)$ \\
& Underweight & $8(3.30)$ \\
& Normal & $154(63.40)$ \\
\hline Physical activity & Overweight & $70(28.80)$ \\
& Obese & $11(4.50)$ \\
\hline
\end{tabular}

${ }^{\mathrm{a}} \mathrm{P}<0.05$

The results of univariate regression analysis presented in Table 2 indicated a strong relationship between physical activity, perceived health, and all its dimensions, except for social health $(\mathrm{P}<0.05)$.

Table 2. Univariate Linear Regression Analysis for the Relationship Between Physical Activity and Perceived Health and Its Dimensions

\begin{tabular}{lccc}
\hline \multirow{2}{*}{ Dependent Variable } & \multicolumn{3}{c}{ Independent Variable } \\
\cline { 2 - 4 } & $\beta$ & $\mathbf{9 5 \%}$ Confidence Interval & P Value \\
\hline Mental & 0.705 & $19.22-74.36$ & 0.077 \\
\hline Emotional & 0.989 & $19.22-74.79$ & 0.034 \\
\hline Social & 0.227 & $23.25-45.88$ & 0.54 \\
\hline Physical & 1.173 & $21.23-17.75$ & 0.003 \\
\hline Spiritual & 1.096 & $23.25-06.51$ & 0.003 \\
\hline Intellectual & 1.09 & $19.22-91.2$ & 0.002 \\
\hline Perceived health & 5.28 & $129.140-03.55$ & 0.003 \\
\hline
\end{tabular}

The results of multivariate linear regression analysis showed the relationship between physical activity and perceived health dimensions (physical, intellectual, social, emotional, spiritual, and mental health) as well as demographic variables (Table 3). Accordingly, no significant relationship was found between physical activity, social health $(\mathrm{P}=0.79, \beta=0.095)$, and mental health $(\mathrm{P}=0.128, \beta=$ 0.58). However, perceived health was significantly associated with age $(\mathrm{P}=0.039, \beta=0.61)$, sex $(\mathrm{P}=0.002, \beta=$ 9.33), and physical activity $(\mathrm{P}=0.002, \beta=5.00)$. Significant positive relationships were also observed between mental health and working experience $(\mathrm{P}=0.014, \beta=0.19)$, intellectual health and age $(\mathrm{P}=0.000, \beta=0.12)$, and intellectual health and physical activity $(\mathrm{P}=0.006, \beta=0.93)$. Besides, physical health was positively associated with age $(\mathrm{P}=0.057, \beta=0.13)$ and physical activity $(\mathrm{P}=0.012, \beta=$ 0.95). Additionally, a significant positive association was observed between spiritual health and $\operatorname{sex}(\mathrm{P}=0.031, \beta=$ $1.45)$ as well as physical activity $(\mathrm{P}=0.004, \beta=1.07)$. Finally, emotional health was positively related to $\operatorname{sex}(\mathrm{P}=0.000, \beta$ $=3.03)$ and physical activity $(\mathrm{P}=0.023, \beta=0.99)$. No significant reverse relationships were observed among the study variables.

\section{Discussion}

The study results indicated that more than half of the staff had mild physical activity, which is in line with the findings of the studies performed by Sadeghpour et al. Verloigne et al. and Caban-Martinezz et al. (16-18). Besides, most of the staff under the present investigation had a normal BMI. In contrast, almost half of the participants of the study by Hojjati and Alipour were overweight and obese (19). Hojjati and Alipour also reported that more than half of their participants were overweight and obese (19).

Based on the results presented in Table 3, physical activity was associated with all dimensions of perceived health, except for social health, which is on the contrary to the results of the study performed by Kim et al. (2012) on Chinese students (20). However, Song and Zhang (2011) assessed the effect of exercise on reduction of behavioral problems among adolescents and came to similar results to those of the present study (21). On the other hand, Sebire et al. evaluated the relationship between exercise self-efficacy and perceived health and came to the conclusion that exercise self-efficacy was not related to social health (22). Of course, social health has to be evaluated with respect to social support dimensions, which is supported by the results obtained by Wallace et al. $(23,24)$.

Considering the relationship between physical activity and mental health, Lee and Russell performed 2 long-term and cross-sectional studies on Australian women. In the long-term research, a weak relationship was observed in 
Table 3. Multivariate Linear Regression Analysis for Perceived Health Dimensions, Demographic Variables, and Physical Activity

\begin{tabular}{|c|c|c|c|c|c|c|c|c|c|c|c|c|c|c|c|c|c|c|c|c|c|}
\hline \multirow{3}{*}{$\begin{array}{l}\text { Studies } \\
\text { Main } \\
\text { Vari- } \\
\text { ables }\end{array}$} & \multicolumn{21}{|c|}{ Dimension's of Perceived Health } \\
\hline & \multicolumn{3}{|c|}{ Emotional Health } & \multicolumn{3}{|c|}{ Spiritual Health } & \multicolumn{3}{|c|}{ Physical Health } & \multicolumn{3}{|c|}{ Intellectual Health } & \multicolumn{3}{|c|}{ Mental Health } & \multicolumn{3}{|c|}{ Social Health } & \multicolumn{3}{|c|}{ Perceived Health } \\
\hline & $\beta$ & $\mathbf{S E}$ & $\mathbf{T}$ & $\beta$ & SE & $\mathbf{t}$ & $\beta$ & SE & t & $\beta$ & SE & $\mathrm{T}$ & $\beta$ & SE & t & $\beta$ & SE & t & $\beta$ & SE & $\mathbf{t}$ \\
\hline Age & 0.07 & 0.08 & 0.92 & 0.06 & 0.06 & 0.95 & 0.13 & 0.06 & $1.91^{\mathrm{a}}$ & 0.12 & 0.03 & $4.12^{\mathrm{b}}$ & $\begin{array}{c}\cdot \\
0.00\end{array}$ & 0.06 & 0.06 & 0.10 & 0.06 & 1.58 & 0.61 & 0.29 & $2.07^{\mathrm{c}}$ \\
\hline Gender & 3.03 & 0.81 & $3.71^{b}$ & 1.45 & 0.67 & $2.16^{\mathrm{c}}$ & . & . & . & . & . & . & . & . & . & . & . & . & 9.33 & 3.02 & $3.09^{\mathrm{b}}$ \\
\hline $\begin{array}{l}\text { Marital } \\
\text { sta- } \\
\text { tus }\end{array}$ & 0.27 & 0.61 & 0.44 & 0.73 & 0.51 & 1.43 & 0.39 & 0.53 & 0.74 & 0.48 & 0.47 & 1.02 & -0.19 & 0.54 & -0.36 & -014 & 0.50 & -0.29 & 2.28 & 2.27 & 1.00 \\
\hline Educati & -0.23 & 0.49 & 0.46 & - & - & . & 0.23 & 0.41 & 0.57 & -0.13 & 0.36 & -0.36 & -0.04 & 0.42 & -0.11 & 0.03 & 0.39 & -0.09 & -1.08 & 1.80 & -0.59 \\
\hline $\begin{array}{l}\text { Field } \\
\text { of } \\
\text { oc- } \\
\text { cu- } \\
\text { pa- } \\
\text { tion }\end{array}$ & 0.50 & 0.37 & -1.32 & -0.38 & 0.31 & -1.21 & . & . & . & 0.26 & 0.29 & -0.89 & . & . & . & . & . & . & 1.92 & 1.40 & -1.37 \\
\hline $\begin{array}{l}\text { Work } \\
\text { Ex- } \\
\text { peri- } \\
\text { ence }\end{array}$ & 0.14 & 0.09 & 1.53 & 0.02 & 0.07 & 0.39 & 0.01 & 0.07 & 0.17 & . & . & . & 0.19 & 0.07 & $2.47^{c}$ & 0.06 & 0.07 & 0.84 & 0.33 & 0.33 & 0.99 \\
\hline BMI & 0.03 & 0.07 & 0.50 & . & . & . & . & . & . & 0.02 & 0.05 & 0.36 & -0.01 & 0.06 & -0.19 & . & . & . & -0.12 & 0.26 & -0.48 \\
\hline $\begin{array}{l}\text { Physica } \\
\text { ac- } \\
\text { tiv- } \\
\text { ity }\end{array}$ & 0.99 & 0.43 & $2.28^{\mathrm{a}}$ & 1.07 & 0.36 & $2.93^{\mathrm{C}}$ & 0.95 & 0.37 & $2.52^{\mathrm{c}}$ & 0.93 & 0.33 & $2.78^{\mathrm{b}}$ & 0.56 & 0.38 & 1.52 & 0.09 & 0.35 & 0.26 & 5.00 & 1.91 & $3.1^{\mathrm{b}}$ \\
\hline
\end{tabular}

this regard. Indeed, the women who had changed from an active to inactive status showed more negative changes in mental health compared to those who had always been inactive (25). However, these results were not in agreement with those of other investigations (26-28).

The findings of our study revealed a strong positive relationship between perceived health and physical activity, which is consistent with the results of the study by Mohammadzadeh et al. (29). Similar results were also obtained by Mohammadzadeh and Hasanzadeh (2003), who believed that taking part in physical activities and exercises was effective in positive perception of actual health or health image (30).

Based on the current study results, physical activity was associated with emotional, intellectual, and physical health. Similarly, Brach et al. reported that the old individuals who did mild to moderate physical activities for 20 - 30 minutes on most days of the week had better physical function compared to the inactive individuals (31). The findings of the study by Sidman were also consistent with those of our investigation (22). Previous studies also showed a relationship between exercise and some dimensions of health. For instance, Bezner, Adams, and Whistler indicated that high physical activity levels were associated with high scores of mental and physical health in PWS (32).

A notable point in this study was that, we used the questionnaires that had been valid on the Iranian population.
Furthermore, the relationship between perceived wellness and physical activity were considered that has not been reported in Iran yet.

One of the limitations of this study was that no studies were previously conducted simultaneously on perceived health, physical activity, and demographic variables; therefore, we did not have a reference for comparison. Another study limitation was dispersion of the colleges of Shiraz University of Medical Sciences, which led to the inability to select the participants through random sampling. Additionally, most of the study participants were female, which might be due to the fact that either the number of female staff was higher compared to the males or the female staff cooperated more in filling out the questionnaires. Thus, the study results could only be generalized to the female staff. Finally, this study was a cross-sectional and could only identify the relationship between the variables at a particular point of time. Hence, further longitudinal studies are recommended to evaluate the changes in these variables over time.

\subsection{Conclusion and Suggestions}

Considering the staff's insufficient physical activity, the strong relationship between physical activity and health as well as its impact on the organization's direct and indirect costs, health promotion programs and policies have to be designed focusing on the staff's physical ac- 
tivity. Furthermore, future longitudinal studies are suggested to be conducted on perceived health and physical activity in various populations considering other beliefs, such as exercise self-efficacy, motivation for exercising, and other health-based measures.

\section{Acknowledgments}

This article was extracted from the Jeyran Ostovarfar's M.Sc thesis in Health Education and Health Promotion financially supported by the research vice-chancellor of Shiraz University of Medical Sciences, Shiraz, Iran (grant No. 93-7315). Hereby, the authors would like to thank the entire staff of Shiraz University of Medical Sciences who cooperated in completing the study questionnaires

\section{References}

1. Alizadeh Z, Mostafaee M, Mazaheri R, Younespour S. Acute Effect of Morning and Afternoon Aerobic Exercise on Appetite of Overweight Women. Asian J Sports Med. 2015;6(2):e24222. doi: 10.5812/asjsm.6(2)20156.24222. [PubMed: 26448839].

2. Ekelund U, Besson H, Luan J, May AM, Sharp SJ, Brage S, et al. Physical activity and gain in abdominal adiposity and body weight: prospective cohort study in 288,498 men and women. Am J Clin Nutr. 2011;93(4):826-35. doi: 10.3945/ajcn.110.006593. [PubMed: 21346093].

3. Ghahremani L, Niknami S, Nazari M. The prediction of physical activity intention and behavior in elderly male residents of a nursing home: a comparison of two behavioral theories. Iran J Med Sci. 2012;37(1):23-31. [PubMed: 23115427].

4. Butler JT. Principles of health education and health promotion. Morton Publishing Company; 1994.

5. Mazloomy Mahmoudabad S, Mohammadi M, Morovati Sharifabad MA. Exercise and Its relation to self efficacy based on stages of change model in employees of Yazd in 2008. J Kerman Univ Med Sci. 2015.

6. Frank E, Tong E, Lobelo F, Carrera J, Duperly J. Physical Activity Levels and Counseling Practices of U.S. Medical Students. Med Sci Sports Exerc. 2008;40(3):413-21. doi: 10.1249/MSS.ob013e31815ff399.

7. Organization WH. Global recommendations on Physical Activity for health. World Health Organization; 2010.

8. Lahart IM, Metsios GS, Nevill AM, Carmichael AR. Physical activity levels in women attending breast screening, receiving chemotherapy and post-breast cancer treatment; a cross-sectional study. Int J Environ Res Public Health. 2014;11(5):5487-96. doi:10.3390/ijerph110505487. [PubMed: 24852599].

9. Jalili L, Yazdi Zadeh H, Sharifi N, Abedi P, Najar S, Asad Mobini E. The relationship between physical activity and the severity of menopause symptoms in menopausal women in Ahvaz, Iran. Iran JObstetr Gynecol Infertil. 2014;17(98):15-23.

10. Hazavehei SMM, Asadi Z, Hassanzadeh A, Shekarchizadeh P. Comparing the effect of two methods of presenting physical education $\Pi$ course on the attitudes and practices of female Students towards regular physical activity in Isfahan University of Medical Sciences. Iran J Med Educ. 2008;8(1):121-31.

11. Estebsari FSD, Mostafayi D, Farahbakhsh M. Increase physical activity for students girl based on PRECEDE Model to Improve physical activity in female student. Hayat. 2010;16(1):48-54.

12. Adams T, Bezner J, Steinhardt M. The conceptualization and measurement of perceived wellness: integrating balance across and within dimensions. Am J Health Promot. 1997;11(3):208-18. [PubMed: 10165100].
13. Adams TB, Bezner JR, Drabbs ME, Zambarano RJ, Steinhardt MA. Conceptualization and measurement of the spiritual and psychological dimensions of wellness in a college population. $J$ Am Coll Health. 2000;48(4):165-73. doi: 10.1080/07448480009595692. [PubMed: 10650734].

14. Adams T, Bezner J, Garner L, Woodruff S. Construct validation of the perceived wellness survey. Am J Health Stud. 1998;14(4):212.

15. Kaveh MH, Ostovarfar J, Keshavarzi S, Ghahremani L. Validation of Perceived Wellness Survey (PWS) in a Sample of Iranian Population. Malaysian J Med Sci. 2016;23(4):46-53. doi:10.21315/mjms2016.23.4.6.

16. Sadeghpour A, Sadeghpour M, Hosseini MS. The relationship of physical activity levels and mental health: a case study at Isfahan University of Medical Sciences, Iran. I Isfahan Med School. 2014;32(274).

17. Verloigne M, Van Lippevelde W, Maes L, Yildirim M, Chinapaw M, Manios Y, et al. Levels of physical activity and sedentary time among 10to 12-year-old boys and girls across 5 European countries using accelerometers: an observational study within the ENERGY-project. Int J Behav Nutr Phys Act. 2012;9:34. doi: 10.1186/1479-5868-9-34. [PubMed: 22462550].

18. Caban-Martinez AJ, Lee DJ, Fleming LE, LeBlanc WG, Arheart KL, ChungBridges $\mathrm{K}$, et al. Leisure-time physical activity levels of the US workforce. Prev Med. 2007;44(5):432-6. doi: 10.1016/j.ypmed.2006.12.017. [PubMed: 17321584].

19. Hojjati Z, AlipourV. Relationship between physical activity and health related anthropometric indices of university female staffs. Bimonth J Hormozgan Univ Med Sci. 2014;18(2):148-55.

20. Kim YS, Park YS, Allegrante JP, Marks R, Ok H, Ok Cho K, et al. Relationship between physical activity and general mental health. Prev Med. 2012;55(5):458-63. doi: 10.1016/j.ypmed.2012.08.021. [PubMed: 22981733].

21. Song Z, Zhang J. Research on the relationship between physical activity and social health of university students. Modern Prevent Med. 2011;16:046.

22. Sebire SJ, Jago R, Fox KR, Page AS, Brockman R, Thompson JL. Associations between children's social functioning and physical activity participation are not mediated by social acceptance: a cross-sectional study. Int J Behav Nutr Phys Act. 2011;8:106. doi: 10.1186/1479-5868-8-106. [PubMed: 21961734].

23. Sidman CL, D'Abundo ML, Hritz N. Exercise self-efficacy and perceived wellness among college students in a basic studies course. Int Electron J Health Educ. 2009;12:162-74.

24. Wallace LS, Buckworth J, Kirby TE, Sherman WM. Characteristics of exercise behavior among college students: application of social cognitive theory to predicting stage of change. Prev Med. 2000;31(5):494505. doi: 10.1006/pmed.2000.0736. [PubMed: 11071829].

25. Wallace LS, Buckworth J. Application of the Transtheoretical Model to Exercise Behavior among Nontraditional College Students. Am J Health Educ. 2013;32(1):39-47. doi:10.1080/19325037.2001.10609396.

26. Lee C, Russell A. Effects of physical activity on emotional well-being among older Australian women.J Psychosomatic Res. 2003;54(2):15560. doi: 10.1016/s0022-3999(02)00414-2.

27. Beebe LH, Tian L, Morris N, Goodwin A, Allen SS, Kuldau J. Effects of Exercise on Mental and Physical Health Parameters of Persons with Schizophrenia. Issues Ment Health Nurs. 2009;26(6):661-76. doi: 10.1080/01612840590959551.

28. Brosnahan J, Steffen LM, Lytle L, Patterson J, Boostrom A. The Relation Between Physical Activity and Mental Health Among Hispanic and Non-Hispanic White Adolescents. Arch Pediatr Adolescent Med. 2004;158(8):818. doi: 10.1001/archpedi.158.8.818.

29. Mortazavi SS, Ardebili HE, Eshaghi SR, Beni RD, Shahsiah M, Botlani S. The Effectiveness of Regular Physical Activity on Mental Health in Elderly. J Isfahan Med School. 2012;29(161).

30. Mohammadzadeh Y, Hasanzadeh K. Determinants of Health and the Cost of Catastrophic Health Expenses in Households. J Knowledge Health. 2016;11(3):8-16. doi:10.1234/knh.v11i3.1320. 
31. Pyle RP, Mc Quivey RW, Brassington GS, Steiner H. High School Student Athletes: Associations Between Intensity of Participation and Health Factors. Clin Pediatr. 2016;42(8):697-701. doi: $10.1177 / 000992280304200805$.
32. Brach JS, Simonsick EM, Kritchevsky S, Yaffe K, Newman AB. The Association Between Physical Function and Lifestyle Activity and Exercise in the Health, Aging and Body Composition Study. J Am Geriatrics Soc. 2004;52(4):502-9. doi: 10.1111/j.1532-5415.2004.52154.x. 